\title{
Considerations on the Species Complex of the Cortelezzii series (Diptera: Psychodidae) and Description of Evandromyia chacuensis sp. nov., a New Phlebotomine Species of the Chaco Region, Argentina
}

\author{
Enrique A. Szelag, ${ }^{1,2,3}$ Juan R. Rosa, ${ }^{1}$ Eunice A. B. Galati, ${ }^{4}$ José D. Andrade Filho, ${ }^{5}$ and \\ Oscar D. Salomón ${ }^{2,3,6}$ \\ 'Instituto de Medicina Regional, Universidad Nacional del Nordeste, Av. Las Heras 727, Chaco, Argentina, ${ }^{2}$ Instituto Nacional \\ de Medicina Tropical, Ministerio de Salud, Misiones, Argentina, ${ }^{3}$ Consejo Nacional de Investigaciones Científicas y Técnicas \\ (CONICET), CABA, Argentina, ${ }^{4}$ Departamento de Epidemiologia, Faculdade de Saúde Pública, Universidade de São Paulo, Av. Dr. \\ Arnaldo 715, São Paulo, Brazil, ${ }^{5}$ Coleção de Flebotomíneos, Centro de Referência Nacional e Internacional para Flebotomíneos, \\ Instituto René Rachou, FIOCRUZ, Av. Augusto de Lima 1715, 30190-002 Belo Horizonte, MG, Brazil, and ${ }^{6}$ corresponding author, \\ e-mail: odanielsalomon@gmail.com
}

Subject Editor: Richard Wilkerson

Received 2 November 2017; Editorial decision 10 February 2018

\begin{abstract}
A new species of phlebotomine sand fly is described and illustrated based on male and female specimens collected in rural and semi-urban areas of the Chaco Province, Argentina. A separation of the Cortelezzii series in two species complexes is proposed, as is a species key for its identification. The morphological characters of the new species permit its inclusion in the Cortelezzii series of genus Evandromyia, subgenus Barrettomyia (Diptera: Psychodidae). The species is named Evandromyia chacuensis sp. nov. Szelag, Rosa, Galati, Andrade Fhilo \& Salomón (Diptera: Psychodidae).
\end{abstract}

Key words: sand fly, phlebotomine, n. sp., new species, Evandromyia

Phlebotominae sand flies (Diptera: Psychodidae) are insects of medical and veterinary importance because some species are able to transmit various pathogens such as Bartonella spp., Phlebovirus spp., and protozoan parasites of the genus Leishmania to susceptible mammalian hosts. In the last $20 \mathrm{yr}$, numerous leishmaniasis outbreaks have been reported in the Chaco bioregion of Argentina (Salomón et al. 2008), with an increase of cases associated with periurban transmission. Of the 37 phlebotomine species recorded in Argentina (Szelag et al. 2016, Fuenzalida and Quintana 2017), 18 were found in the Chaco province. The genus Evandromyia Mangabeira, 1941 is one of the most frequent and widespread in the country. According to Galati (2003), this genus consists of three subgenera: Evandromyia s. str, Aldamyia Galati, 1995 and Barrettomyia Martins \& Silva, 1968. Of the six species recorded in Argentina, Evandromyia aldafalcaoae (Santos, Andrade Filho \& Honer 2001), Evandromyia termitophila (Martins, Falcão \& Silva, 1964), and Evandromyia evandroi (Costa Lima \& Antunes, 1936) are included in the Aldamyia subgenus. Three species, Evandromyia cortelezzii (Brèthes, 1923), Evandromyia corumbaensis (Galati, Nunes, Oshiro \& Rego, 1989) and Evandromyia sallesi (Galvão \& Coutinho, 1939) are included in the Cortelezzii series of subgenus Barrettomyia. All of these species have been recorded in the Chaco province, with the exception of Ev. evandroi, which is restricted to Misiones Province.

The Cortelezzii series was previously formed by five species: a noncryptic species: Evandromyia edwardsi (Mangabeira, 1941), and four other cryptic species: Evandromyia cortelezzii, Ev. sallesi, Ev. Corumbaensis, and Evandromyia spelunca Carvalho, Brazil, Sanguinette \&Andrade Filho, 2011. Males of these cryptic species can be distinguished using morphological characters, while females are difficult to differentiate. This is why females of these cryptic species were often identified not to species but as belonging to the 'Cortelezzii complex', a term used to differentiate them to Ev. edwardsi in the same series (Galati et al. 1989, Carvalho et al. 2011). Currently, the term Cortelezzii complex is no longer needed after the exclusion of Ev. edwardsi from the Cortelezzii series (Galati 2017). However, based on morphological characters discussed below we consider that the Cortelezzii series could be divided in two groups of cryptic species well differentiated, reconsidering the need for the informal category of complex to refer them.

It is important to note that females of the Cortelezzii series, collected in the dry area of Chaco Province, have been found with Leishmania braziliensis DNA (Rosa et al. 2012), underscoring the 
importance of this species group in the region and the need for correct identification.

In the present paper, a new phlebotomine sand fly species from Chaco Province, Argentina, is described based on morphological characters of both sexes collected in rural and semi-urban areas of the province. A separation of the Cortelezzii series in two species complexes is proposed as is a species identification key based on Galati (2003).

\section{Materials and Methods}

Collections were undertaken in known cutaneous leishmaniasis foci in two regions (Western Chaco and Eastern Chaco) of Chaco Province, between 2006 and 2013 (Rosa et al. 2010, Szelag et al. 2016). Captures were made monthly with mini CDC light traps (Sudia and Chamberlain 1962) installed $1.5 \mathrm{~m}$ above ground level from $7 \mathrm{pm}$ to $7 \mathrm{am}$. In and around houses, the traps were placed indoors or on the veranda and in pens or animal resting places. Away from houses, they were placed in forest patches at least 100 $\mathrm{m}$ from habitations. In the Western Chaco region, captures were made from 2006 to 2008 for two consecutive nights each month in Fortín Arenales (S24 58 $18^{\prime \prime}-\mathrm{W} 61^{\circ} 21^{\prime} 25^{\prime \prime}$ ), approximately $40 \mathrm{~km}$ from the city of Misión Nueva Pompeya (capital of Comandante Brown Department). In the Eastern Chaco region, captures were carried out between 2010 and 2013 in the municipalities of Margarita

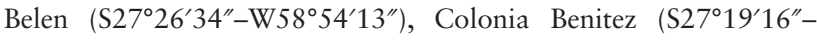
W5 $\left.58^{\circ} 59^{\prime} 53^{\prime \prime}\right)$ and Resistencia (S27 $\left.16^{\prime} 48^{\prime \prime}-\mathrm{W} 59^{\circ} 1^{\prime} 11^{\prime \prime}\right)$. Specimens were cleared as described by Forattini (1973) and mounted in Canada balsam. Morphological structures were measured under a binocular microscope with a micrometer eyepiece (CX31RTSF; OLYMPUS CORP., Tokyo, Japan) and drawings were made using a camera lucida. Measurements (in micrometers) were made for the male holotype, the female allotype, and paratypes. The average, standard deviation, and numbers of paratype specimens examined are shown in parentheses after the holotype and allotype measurements. Measurements of some characters were not made, because some structures were lost during the preparation and mounting process. The nomenclature and abbreviations are based on Galati et al. (2017), and the classification scheme follows Galati (2003, 2017). The new species is described on the basis of 11 males and 12 females, caught at the sampling sites and, to ensure the female/male association, specimens were compared with second and third generations of a colony in the experimental insectaries of the Instituto de Medicina Regional, Universidad Nacional del Nordeste (IMRUNNE). Further information of sampling sites and associated fauna could be found in Szelag et. al (2016).

\section{Other species}

Evandromyia corumbaensis: BRAZIL-Mato Grosso do Sul state, Corumbá municipality (10 ơ, 10 ९); Evandromyia cortelezzii: ARGENTINA-Chaco state, Resistencia municipality (10 $\left.\mathrm{o}^{\star}\right)$, Misión Nueva Pompeya municipality (10 o", 10 \&); Evandromyia sallesi: ARGENTINA-Chaco state, Resistencia municipality (5 ơ), Margarita Belén municipality (10 ơ), Misión Nueva Pompeya municipality (10 o", 10 ९); Evandromyia spelunca: BRAZIL: type locality—original description.

\section{Nomenclature}

This paper and the nomenclatural act(s) it contains have been registered in Zoobank (www.zoobank.org), the official register of the International Commission on Zoological Nomenclature. The LSID
(Life Science Identifier) number of the publication is urn:Isid:zoobank. org:pub:52D85D20-F27A-4967-9DDF-716E4FA14BE3

\section{Evandromyia (Barrettomyia) chacuensis Szelag, Rosa, Galati, Andrade Fhilo \& Salomón sp. nov.}

(Zoobank LSID: urn:lsid:zoobank.org:act:F6AC6450-843A-4518BAAD-A5490630D292)

(Figs. 1-6)

\section{Male HOLOTYPE}

Medium sized, general color light brown.

Head (Fig. 1A) length $363.6(352 ; 7.5 ; n=10)$, width 283 (286; $8.3 ; n=10)$. Head length/head width ratio 1.29: 1 (1.23: 1; 0.04; $n=10)$. Eye $136(139 ; 6.2 ; n=10)$ long and $80(80 ; 2.9 ; n=10)$ wide; eye length/head length $0.37: 1(0.39: 1 ; 0.02 ; n=10)$. Clypeus $136(129 ; 3.9 ; n=10)$ long and $90(91 ; 2.4 ; n=10)$ wide; clypeus length/head length ratio $0.37: 1(0.37: 1 ; 0.01 ; n=10)$. Interocular distance 133 (124; 9.0; $n=10$ ). Labrum-epipharynx (LE) 163 (167; $7.0 ; n=10)$. LE/head length $0.45: 1$ (0.47: $1 ; 0.02 ; n=10)$. Labial suture forming a fork. First flagellomere with simple ascoids, internal one more basal than external one, flagellomeres II to XIII with simple and short ascoids, implanted at same level, not reaching the next flagellomere. Flagellomere lengths: FI 233 (232; 4.0; $n=10)$; FII 118 (112; 3.6; $n=10)$; FIII 115 (114; 4.3; $n=10)$; FXIII 68 (64; 3.1; $n=10)$; FXIV 68 (66; 4.0; $n=10)$. Ratios: FI / LE 1.43:1 (1.39: 1 ; $0.06 ; n=10)$. FI /head length $0.64: 1(0.66: 1 ; 0.02 ; n=10)$. FI, FII, FIII, FX, FXI, FXII, FXIII and FIVX with papillae. Palpal formula 1.2.4.3.5 (1.2.4.3.5; $n=10)$. Palpal segment lengths: PI 25 (28; 2.1; $n=10)$; PII 100 (101; 2.9; $n=10)$; PIII 146 (139; 3.4; $n=10)$; PIV

A
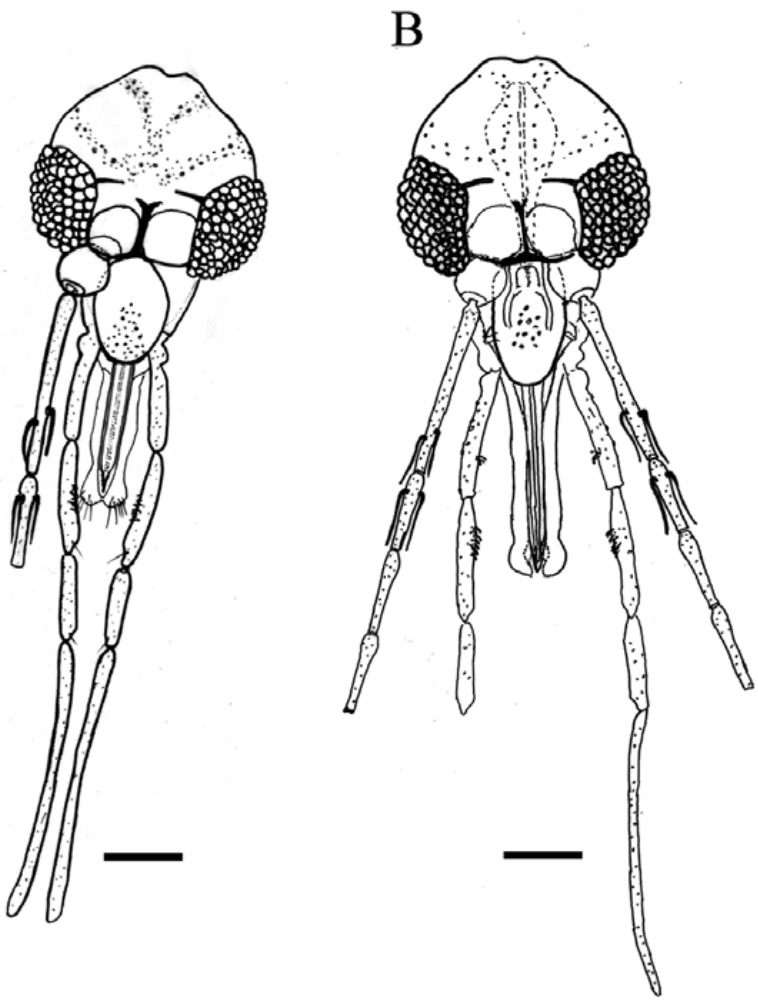

Fig. 1. Evandromyia (Barrettomyia) chacuensis sp. nov.: (A) male paratype head, frontal view and (B) female paratype head, frontal view. Bar $=100 \mu \mathrm{m}$. 
113 (105; 10.9; $n=10)$; PV 356 (329; 32.4; $n=10)$. Newstead's sensilla inserted medially on palpal segment III.

Cervix. Ventrocervical sensilla present.

Thorax. Proepimeral setae present $6-6[(5-6 ; n=4)(7-6 ; n=1)$, $(6-6 ; n=2),(6-4 ; n=1),(5-5 ; n=1),(4-3 ; n=1)] ; 11-16$ upper anepisternal setae; setae on anterior katepisternum margin absent $(n=10)$. Wing (Fig. 2A), $1,717(1,679 ; 80.6 ; n=10)$ long and 465 $(452 ; 10.4 ; n=10)$ at maximum width. Length/width ratio 3.69 : 1 (3.71: $1 ; 0.06 ; n=10)$. Length of vein sections: alpha 313 (321; 21.7; $n=10)$; beta $222(198 ; 69.9 ; n=10)$; gamma $222(237 ; 86.8$; $n=10)$; delta 91 (79; 33.6; $n=10)$; epsilon $485(506 ; 15.4 ; n=10)$; pi $141(125 ; 45 ; n=10)$; R4 808 (820; 23.2; $n=10)$; R5 1,111 $(1,109 ; 6.4 ; n=10)$. Leg length: anterior, median and posterior, respectively: coxa $273(266 ; 8.3 ; n=10), 273(263 ; 11.7 ; n=10)$, $283(265 ; 15.7 ; n=10)$; femur $657(638 ; 18.9 ; n=10), 636(623$; $12.4 ; n=9)$ and $727(724 ; 16.8 ; n=9)$; tibia $747(700 ; 26.5 ; n=10)$, $808(843 ; 29.9 ; n=9)$ and $1,061(1,048 ; 31.9 ; n=9)$; tarsomere I $434(422 ; 11.5 ; n=10), 505(499 ; 15.2 ; n=9)$ and $606(584 ; 14.1$; $n=9)$; tarsomeres II+III+IV+V $566(566 ; 13.5 ; n=10), 596$ (602; $17.6 ; n=9)$, and $616(636 ; 13.4 ; n=9)$.

Abdomen. Presence of tergal papillae on central area of sixth and seventh tergites, without deciduous bristle scars between them. Terminalia (Fig. 3). Gonostylus $153(152 ; 1.8 ; n=10)$ long, 38 (35; $3.0 ; n=10)$ maximum width, with four spines: one apical, one upper external inserted on tubercle in middle of segment, and two finer spines (lower external and internal) implanted almost at same level in basal third. Subterminal spine present. Gonocoxite 246 (245; 3.9; $n=10)$ long and wide $93(102 ; 5.9 ; n=10)$, with tuft containing three long, slender setae inserted on small unilobed tubercle, and six to eight shorter spine-like bristles inserted on globose upper area. Tuft surrounded by distinct hyaline area with small pigmented area on base. Paramere dorsal margin length $146(143 ; 7.2 ; n=10)$; structure thicker at base, narrower in middle and wide at apex; dorsal margin of the apex convex, while ventral margin presents ventral projection with shape like that of a bird's head with beak pointing downward. Proximal limits of the dorsal and ventral expansions are almost at same level withformer being a little bit more apical than latter (Fig. 3). Paramere with longitudinal suture on apical half that divides dorsal and ventral margins; setae implanted almost along entire length. Epandrial lobe $351(348 ; 9.2 ; n=10)$ long and 33 (33; 2.7; $n=10)$ wide. Epandrial lobe/gonocoxite ratio 1.43:1 (1.42:1; $0.03 ; n=10)$. Parameral sheath conical and sclerotized. Aedeagal ducts (Fig. 4) $475(472 ; 15.8 ; n=10)$ long and $4(3 ; 1.03 ; n=10)$ wide, with simple tips. Length of sperm pump $158(156 ; 2.6 ; n=10)$. Aedeagal ducts/sperm pump ratio $3: 1(3.02: 1 ; 0.14 ; n=10)$.

\section{Female PARATYPES}

Medium size, general color light brown.

Head (Fig. 1B) length 394 (404; 18.07; $n=11)$, width 293 (300.25; 11.15; $n=11)$. Head length/head width ratio $1.34: 1$ $(1.35 ; 0.07 ; n=11)$. Eye $141(149.23 ; 7.81 ; n=11)$ long and 100 $(91.27 ; 7.03 ; n=11)$ wide; eye length/head length $1.40: 1$ (1.64: $1 ; 0.15 ; n=11)$. Clypeus $143(149.46 ; 10.55 ; n=11)$ long and 93 (93.33; $2.46 ; n=11$ ) wide; clypeus length/head length ratio 0.36 : 1 (0.37: $1 ; 0.01 ; n=11)$. Interocular distance $138(141.70 ; 4.81$; $n=11)$. Labrum-epipharynx (LE) $233(232.97 ; 6.99 ; n=11)$. LE/ head length 0.59: 1 (0.58: 1 ; 0.02; $n=11)$. Labial suture forked. Flagellomeres with simple ascoids, in FI the internal one more basal than external one; on FII apex of ascoids reaches next segment. Flagellomere lengths: FI 221 (224.53; 10.67; $n=11)$; FII 100 (104.05; 2.60; $n=11)$; FIII $103(104.96 ; 3.14 ; n=11)$; FXIII 68 (63.75; 2.42; $n=11)$; FXIV 60 (56.22; 3.17; $n=11)$. Ratios: FI/ LE 0.95: 1 (0.96: 1 ; 0.04; $n=11$ ); FI/ FIII 2.15: 1 (2.14: 1 ; $0.06 ; n=11)$. FI/head length $0.56: 1$ (0.56: $1 ; 0.01 ; n=11)$ FI, FII, FIII, FX, FXI, FXII, FXIII and FIV with papilla. Palpal formula 1.4.2.3.5 (1.4.2.3.5; $n=10)$ Palpal segment lengths: PI 33 (34.23; 2.03; $n=11)$; PII 123 (122.08; 4.67; $n=11)$; PIII 151(154.62; 5.18; $n=10)$; PIV 103 (109.94; 4.85; $n=10)$; PV 341 (339.35; 14.29; $n=10)$. Newstead's sensilla inserted medially on palpal segment II and III. Cibarium with four well-developed posterior (horizontal) teeth, equidistant, stilettiform, with broadened (not fused) base. Anterior (vertical) teeth present but not well-developed, slightly schlerotized and sometimes difficult to distinguish. Four anterior teeth arranged in single line forming arch on base of posterior teeth (Fig. 5). Lateral teeth evident. Sclerotized area conical and sclerotized arch incomplete. Pharynx unarmed. Lacinia of maxilla with 6-8 external teeth in single longitudinal row.
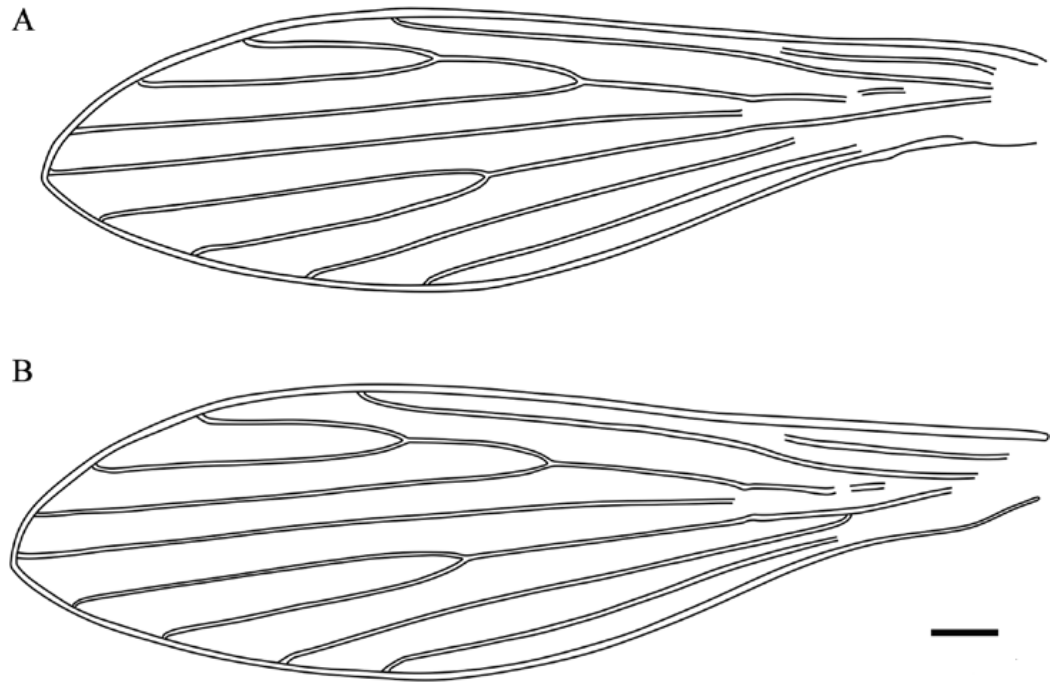

Fig. 2. Evandromyia (Barrettomyia) chacuensis sp. nov.: (A) male holotype wing and (B) female paratype wing. Bar $=100 \mu \mathrm{m}$. 


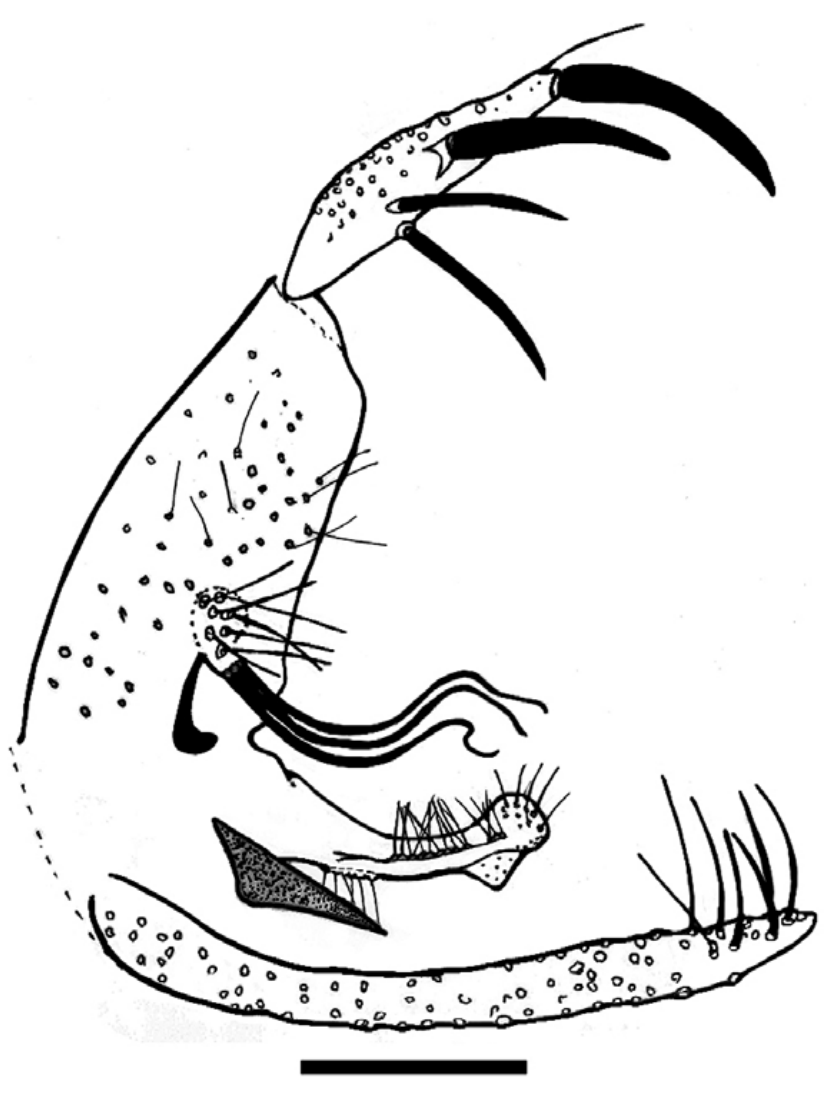

Fig. 3. Evandromyia (Barrettomyia) chacuensis sp. nov. male holotype: terminalia. Bar $=100 \mu \mathrm{m}$.

Cervix. Ventrocervical sensilla present.

Thorax. proepimeral setae present, $4-4[(4-4 ; n=2)(4-5 ; n=1),(5-5$; $n=2),(5-6 ; n=4),(6-6 ; n=2)] ; 13-19$ upper anepisternal setae; setae on anterior katepisternum margin absent. Wing (Fig. 2B), 1,818 $(1,798.81 ; 27.54 ; n=10)$ long and $505(517.12 ; 33.26 ; n=10)$ at maximum width. Length/width ratio 3.6: 1 (3.49: $1 ; 0.23 n=10)$. Length of the vein sections: alpha $333(370.67 ; 41.52 ; n=10)$; beta 222 (244.42; 12.42; $n=10)$; gamma 323 (289.87; 23.83; $n=10)$; delta $81(106.05 ; 15.24 ; n=10)$, epsilon 485 (526.21; 53.96; $n=10)$; pi 141 (137.36; 12.78; $n=10)$; R4 828 (879.71; 54.17; $n=10)$; R5 1,040 (1,166; 74.58; $n=9)$. Leg length, anterior, median and posterior, respectively: coxa $273(291.98 ; 19.40 ; n=11), 273$ (285.55; 16.34; $n=11), 273(286.47 ; 18.22 ; n=11)$; femur 667 $(692.41 ; 32.77 ; n=9), 657(685.68 ; 38.94 ; n=9)$, and $758(789.82$; $37.73 ; n=10)$; tibia $707(726.08 ; 43.86 ; n=9), 859(889.92 ; 45.01$; $n=9)$, and $1,061(1,103.93 ; 51.73 ; n=10)$; tarsomere I $404(435.42$; $27.40 ; n=9), 485(501.63 ; 30.30 ; n=9)$, and $576(618.12 ; 38.33$; $n=10)$; tarsomeres II+III+IV+V $545(587.06 ; 29.78 ; n=8), 616$ $(623.31 ; 19.96 ; n=7)$, and $687(718.54 ; 41.84 ; n=7)$.

Abdomen. Spermathecae globular (Fig. 6), 13 (12.55; 1.12; $n=11$ ) long by $18(19.17 ; 1.27 ; n=11)$ maximum width. Apical knob 10 $(12.32 ; 0.76 ; n=11)$ long, with fine bristles in the apex. Sperm ducts smooth-walled, individual sperm duct length 228 (230.24; 8.10; $n=11)$ width $3(3.65 ; 0.38 ; n=11)$ pre-apical; common duct length $30(27.84 ; 2.09 n=11)$. Spermatheca width/ individual sperm duct width (preapical) ratio: $6: 1(5.25: 1 ; 0.60 ; n=11)$. Individual sperm duct length/common sperm duct length ratio: $7.58: 1$ (8.32: $1 ; 0.76$;

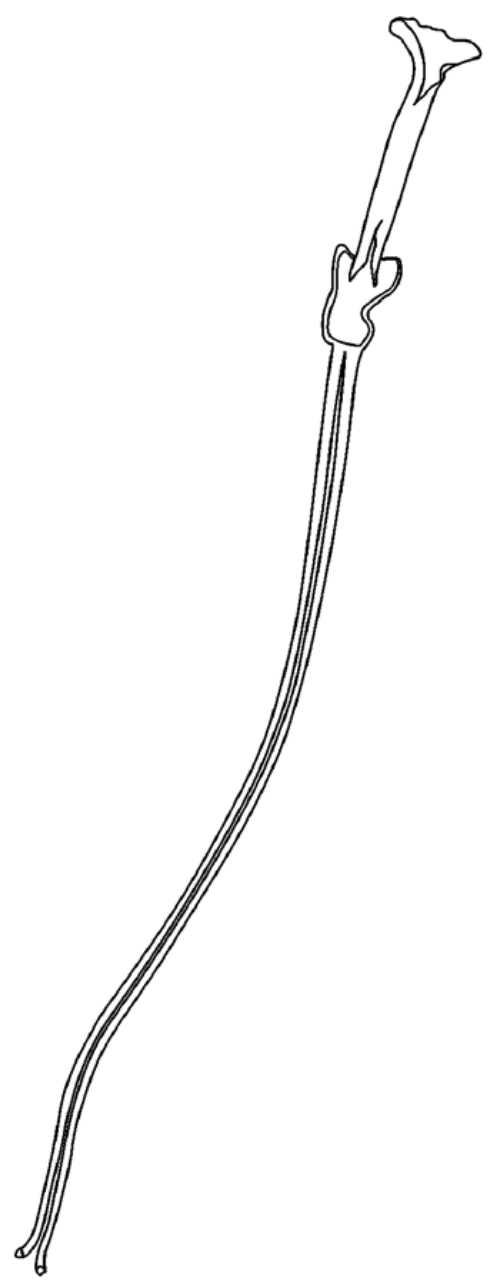

Fig. 4. Evandromyia (Barrettomyia) chacuensis sp. nov. male holotype: sperm pump and aedeagal ducts. Bar $=100 \mu \mathrm{m}$.

$n=11)$. Individual sperm ducts length/rod height of genital fork 2.27: $1(2.36 ; 1.70 ; n=4)$.

\section{Type Material}

HOLOTYPE: 1 o", Misión Nueva Pompeya, CH, 15-X-2008, Rural area of Paraje Fortín Arenales, Szelag E.A. and Rosa J.R.. PARATYPES: 1 ơ, Colonia Benítez, CH, 03-XI-2010, Peridomicile in Rural Area, Szelag E.A. and Rosa J.R.; 1 on, Resistencia, CH, 09-IV-2012, Monte Alto periurban area, Szelag E.A. and Rosa J.R.; 1 o", Resistencia, CH, 17-I-2013, Monte Alto periurban area, Szelag E.A. and Rosa J.R.; $7 \sigma^{\prime \prime}$ and $12 \%$ were obtained from the second and third generations of a colony in the experimental insectaries of the Instituto de Medicina Regional, Universidad Nacional del Nordeste (IMR-UNNE) to ensure the female/male association. The geographic origins of the colony and sample data are the same as those of the Holotype. The voucher specimens will be deposited in the Phlebotomine Sand fly Collection of the Instituto-Fundación Miguel Lillo (I-FML), San Miguel de Tucumán, Argentina.

Type locality: The holotype was collected in ARGENTINA, Chaco, Comandante Brown Department, Misión Nueva Pompeya $\left(24^{\circ} 58^{\prime} 7.5^{\prime \prime} \mathrm{S}-61^{\circ} 21^{\prime} 1.1^{\prime \prime} \mathrm{W}\right)$, in the Chaco bioregion in the Dry Chaco subregion. 


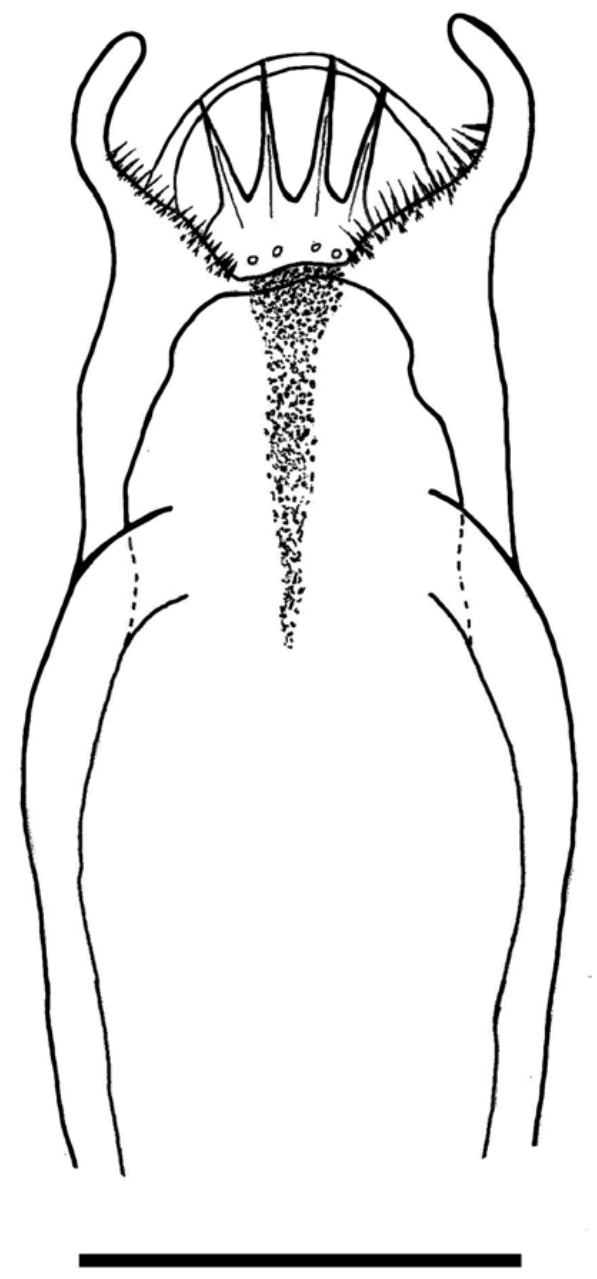

Fig. 5. Evandromyia (Barrettomyia) chacuensis sp. nov. female paratype: cibarium. Bar $=50 \mu \mathrm{m}$.

\section{Distribution}

This species was found in three municipalities of the Chaco province. Misión Nueva Pompeya located in the Dry Chaco bioregion north of the province, and Colonia Benítez and Resistencia in the Humid Chaco bioregion, South of the province.

\section{Etymology}

The name Evandromyia chacuensis sp. nov. has been taken from the word 'chacu' used to name a hunting territory or the hunting technique in the native people's language, from which the Hispanic name of the "Chaco" region is derived.

\section{Discussion}

The morphological characters of the new species permit its inclusion in the Cortelezzii series of the genus Evandromyia (Barretomyia). Currently, after the exclusion of Ev. edwardsi, this series consists of a group of four cryptic species: Ev. corumbaensis, Ev. cortelezzii, Ev. sallesi and Ev. spelunca (Galati 2017). Nevertheless, based on the description of the new species, and differences observed between the spermathecae, individual sperm duct, cibarium, aedeagal ducts and sperm pump, we considered that we can clearly separate the Cortelezzii series in two groups of species. One formed by

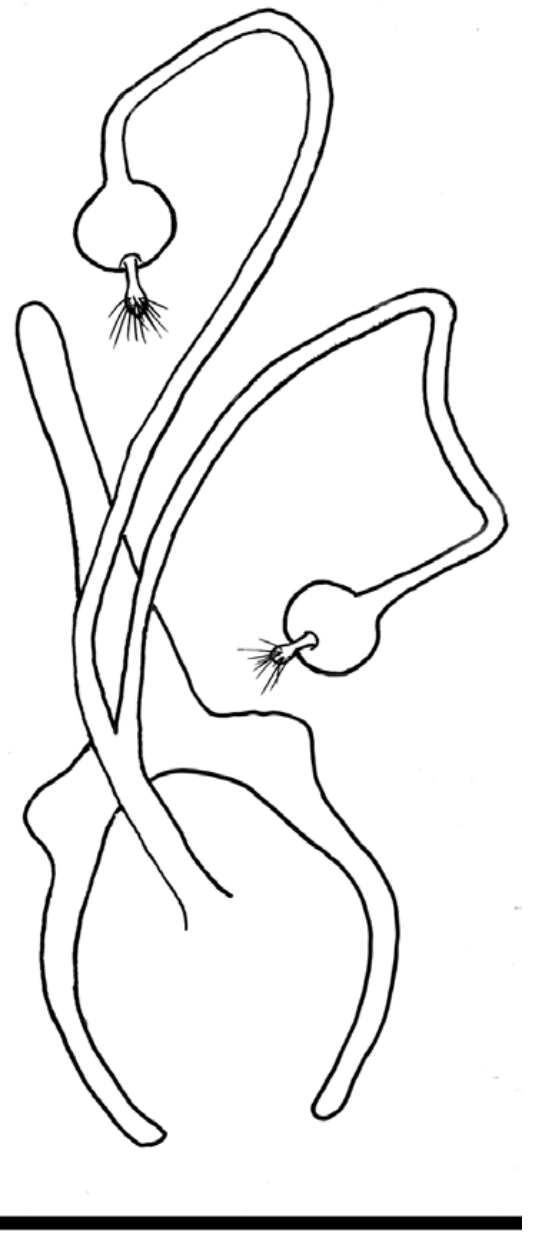

Fig. 6. Evandromyia (Barrettomyia) chacuensis sp. nov. female paratype: spermathecae. Bar $=100 \mu \mathrm{m}$.

Ev. cortelezzii and Ev. sallesi, that we propose to continue calling Cortelezzii complex, the females presenting short individual sperm ducts of almost the same length as the height of the stem of the genital fork; the males being differentiated by the ratio between the length of the aedeagal ducts/sperm pump $\leq 2.3$. The other group, represented by Ev. corumbaensis, Ev. spelunca, and Ev. chacuensis sp. nov., we propose to name the Corumbaensis complex, with females presenting individual sperm ducts 2-2.5 times longer than the height of the stem of the genital fork, and males with the aedeagal ducts $\geq 2.7$ times the length of the sperm pump.

As previously explained the new species presents more similarities to Ev. corumbaensis and Ev. spelunca but can be differentiated by the internal suture, curvature and shape of the paramere and by the gonocoxite tuft (Table 1). The shape of the paramere differentiates Ev. chacuensis sp. nov. and Ev. corumbaensis from Ev. spelunca (see Fig. 7B) by the dorsal curvature of the paramere, more evident in the two former species, resulting in a thinner neck in the middle of the segment (Fig. 7A). Also, in Ev. corumbaensis, Ev. sallesi, Ev. cortelezzii, and Ev. chacuensis sp. nov., the distal portion of the paramere ends in a clearly differentiated rounded head that suggests a bird's head or a hood with a ventral protuberance, like a bird's beak (Galati et al. 1989; Fig. 7C and D), while in Ev. spelunca, this rounded head is not so clearly differentiated because its dorsal margin extends up to the middle of the paramere, giving the head an ovoid shape (see Fig. 7B). Further, the shape and size of the paramere 
Table 1. Morphological comparison between males and females of Cortelezzii series species

\begin{tabular}{|c|c|c|c|c|c|c|}
\hline \multirow[b]{2}{*}{$\begin{array}{l}\text { Cortelezzii series } \\
\text { species }\end{array}$} & \multicolumn{3}{|c|}{ Male } & \multicolumn{3}{|c|}{ Female } \\
\hline & Paramere body & Paramere head & Gonocoxite tuft* & $\begin{array}{c}\text { Individual spermathecal } \\
\text { ducts }\end{array}$ & Spermathecae & Clypeus \\
\hline Ev. sallesi & $\begin{array}{l}\text { Robust } \\
\text { (rectangular) }\end{array}$ & $\begin{array}{l}\text { Hood-like } \\
\text { structure }\end{array}$ & $\begin{array}{l}4 \text { long bristles }(2+2) \text {; } \\
3-4 \text { spiniform } \\
\text { bristles }\end{array}$ & $\begin{array}{l}1-1.5 \text { times longer than } \\
\text { the stem height of the } \\
\text { genital fork }\end{array}$ & $\begin{array}{l}3 \text { times wider than the } \\
\text { individual ducts }\end{array}$ & $\begin{array}{l}\text { shorter or equal to } \\
\text { the eye length }\end{array}$ \\
\hline Ev. cortelezzii & $\begin{array}{l}\text { Slender (dorsal } \\
\text { margin concave) }\end{array}$ & Rounded head & $\begin{array}{l}5 \text { long bristles }(3+2) \text {; } \\
3-5 \text { spiniform } \\
\text { bristles }\end{array}$ & $\begin{array}{l}1-1.5 \text { times longer than } \\
\text { the stem height of the } \\
\text { genital fork }\end{array}$ & $\begin{array}{l}3 \text { times wider than the } \\
\text { individual ducts }\end{array}$ & $\begin{array}{l}\text { shorter or equal to } \\
\text { the eye length }\end{array}$ \\
\hline Ev. corumbaensis & $\begin{array}{l}\text { Slender (dorsal } \\
\text { margin concave) }\end{array}$ & Rounded head & $\begin{array}{l}7 \text { long bristles }(4+3) \text {; } \\
3-4 \text { spiniform } \\
\text { bristles }\end{array}$ & $\begin{array}{l}2-3 \text { times longer than } \\
\text { the stem height of the } \\
\text { genital fork }\end{array}$ & $\begin{array}{l}6 \text { times wider than the } \\
\text { individual ducts }\end{array}$ & $\begin{array}{l}\text { longer than the } \\
\text { eye length }\end{array}$ \\
\hline Ev. chacuensis & $\begin{array}{l}\text { Slender (dorsal } \\
\text { margin concave) }\end{array}$ & Rounded head & $\begin{array}{l}3 \text { long bristles; } 6-8 \\
\text { spiniform bristles }\end{array}$ & $\begin{array}{l}2-3 \text { times longer than } \\
\text { the stem height of the } \\
\text { genital fork }\end{array}$ & $\begin{array}{l}6 \text { times wider than the } \\
\text { individual ducts }\end{array}$ & $\begin{array}{l}\text { shorter or equal to } \\
\text { the eye length }\end{array}$ \\
\hline Ev. spelunca & $\begin{array}{l}\text { Slender (dorsal } \\
\text { margin concave) }\end{array}$ & $\begin{array}{l}\text { Ovoid-shaped } \\
\text { head }\end{array}$ & $\begin{array}{l}4 \text { long bristles; } 2 \\
\text { spiniform bristles }\end{array}$ & $\begin{array}{l}2-3 \text { times longer than } \\
\text { the stem height of the } \\
\text { genital fork }\end{array}$ & $\begin{array}{l}6 \text { times wider than the } \\
\text { individual ducts }\end{array}$ & $\begin{array}{l}\text { longer than the } \\
\text { eye length }\end{array}$ \\
\hline
\end{tabular}

Gonocoxite tuft*: the number of long bristles inserted in different tubercles is presented in parentheses.

differentiate them from Ev. corumbaensis, this last being longer and slenderer due to the pronounced dorsal curvature (Fig. 7A).

In the proposed new species, as in Ev. spelunca, the suture that divides the paramere is more central that in the other species and runs almost the entire length of the paramere. This suture is also evident in Ev. cortelezzii and Ev. corumbaensis, in the latter, however, being positioned more dorsally (Fig. 7).

Evandromyia chacuensis sp. nov. can be distinguished from Ev. sallesi and Ev. cortelezzii by the aedeagal ducts/sperm pump ratio, as previously described, but also by the shape of the paramere, the aspect of which is more similar to that of Ev. cortelezzii, and clearly different from the robust paramere of Ev. sallesi (Fig. 7).

Further, the more conspicuous character for the differentiation of these species is the gonocoxite tuft. The tufts present a small pigmented area on it base, and two different kinds of bristles: the longer slender and more conspicuous ones implanted in a tubercle that can be on one and the same lobe or on different lobes; and shorter less conspicuous spine-like bristles inserted on the upper side of the tuft. All the species of the Cortelezzii series present well differentiated tufts that vary in shape, number and implantation of the bristles (Table 1). In Ev. chacuensis sp. nov. (Fig. 3), the tuft is represented by 3 long, wide and well developed bristles implanted on a unilobed tubercle, and 6-8 short spine-like bristles implanted on a globose upper area of the tuft.In Ev. corumbaensis the tuft has 5-7 (most commonly 7) long, thin bristles implanted in two different lobes of the tubercle, and 3-4 (most commonly 4) spiniform bristles in a position slightly more apical than the other. Also, as previously explained, there are differences in the sperm pump and aedeagal ducts; in the species of the Corumbaensis complex the aedeagal ducts are thinner and longer and the ratio between the length of the aedeagal ducts/sperm pump 2.7 to 3.0 times greater, while in the Cortelezzii complex the ratio is $\leq 2$.

Distinction of the females of the other species of the Corumbaensis complex is more difficult and has not always been possible. However, the new species can be distinguished from the species of the Cortelezzii complex by the spermathecae and characteristics of their ducts, both individual and common ducts being noticeably longer in the Corumbaensis complex (Table 1). Evandromyia chacuensis sp. nov. females can also be differentiated from Corumbaensis complex females by the eye/clypeus length ratio, the eye length in the former being equal or sub-equal to the clypeus as observed for the Cortelezzii complex, while Corumbaensis complex females have the clypeus longer than the eye (however, intra-species variations were observed). The characteristics of the cibarium were sufficient to distinguish the females of both complexes from each other but not between those of species of the same complex. The distance between the area of the implantation of the vertical teeth and the base of the cibarium arch is greater than the width of the middle of the segment in the Corumbaensis complex, while it is wider than longer in the Cortelezzii complex. Further, in the new species, the four vertical teeth are arranged in a single line in a less conspicuous arc than in Ev. spelunca. In addition, the vertical teeth are smaller and difficult to observe in most cases, while in the other species of the Cortelezzii series the teeth are bigger, more chitinous and easier to observe.

In the Chaco region of Argentina, all the species of the Cortelezzii series have been reported, with the exception of Ev. spelunca, probably due to the latter's caverniculous habitat preferences (Carvalho et al. 2011) as caves are rare in the Chaco landscape. However, reports of the distribution of Ev. cortelezzii and Ev. sallesi extend to the center of the country, in Cordoba Province (Visintin et al. 2016), suggesting that the Cortelezzii complex has a broader thermotolerance permitting colonization of southern provinces, while the Corumbaensis complex is restricted to the warmer environments in the north of the country. Further projects may focus on the phylogenetic status of this species group, supporting or disproving these morphological findings. Its sympatry in Argentina should be considered for proper identification in further studies.

\section{Identification Key for Males and Females of the Evandromyia (Barretomyia) Cortelezzii Series}

\section{Males}

1 Aedeagal ducts/sperm pump ratio less than 2.3: 1.0 ..(Cortelezzii complex) 2

Aedeagal ducts/sperm pump ratio 2.7-3.0: 1.0 (Corumbaensis complex) 3 
A
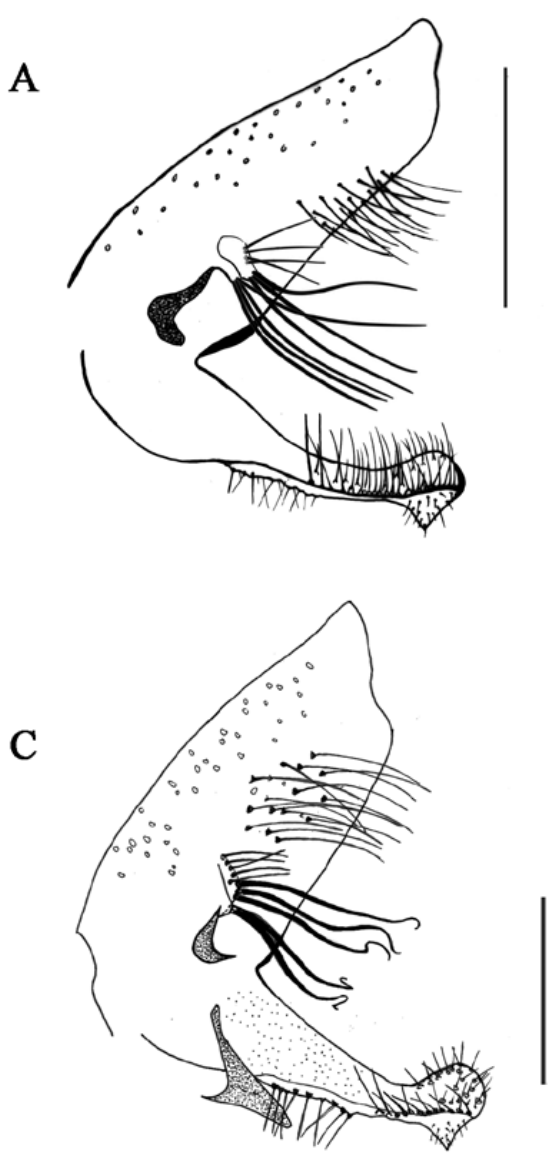

B

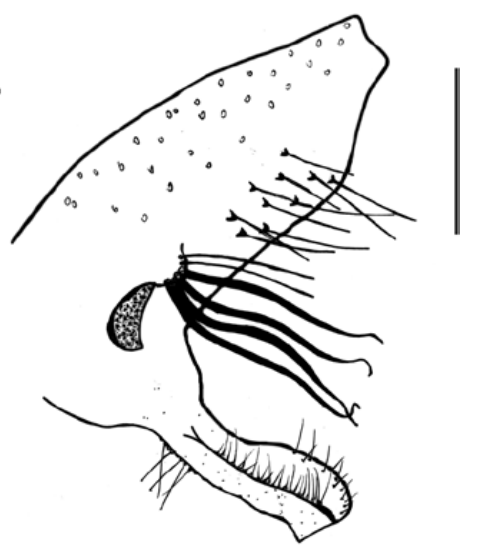

$\mathrm{D}$

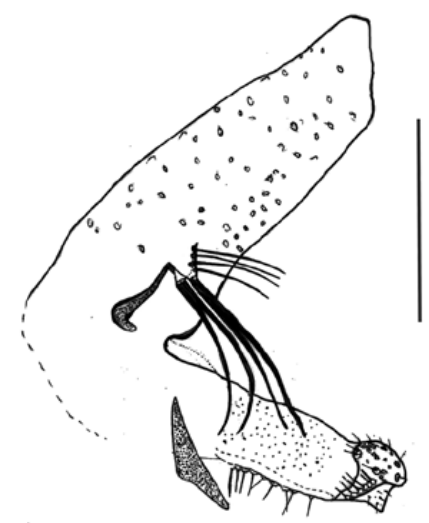

Fig. 7. Male terminalia of (A) Ev. corumbaensis, (B) Ev. spelunca, (C) Ev. cortelezzii and (D) Ev. sallesi. Bar $=100 \mu \mathrm{m}$.

2 (1) Paramere robust (Fig. 7D), rectangular from the base to the apical region, apically with a hood-like structure; gonocoxite tuft with four long bristles inserted on different lobes of the tubercle $(2+2)$, and 3-4 upper short bristles.

Ev. (Bar.) sallesi

Paramere slender (Fig 7C), with a concavity on its dorsal margin, apically with no hood-like structure; gonocoxite tuft with five long bristles inserted on different lobes of the tubercle $(3+2)$, and 3-5 upper short bristles.

Ev. (Bar.) cortelezzii

3 (1) Clypeus longer than the eye length; gonocoxite basal tuft with 2-4 upper short spiniform bristles and 4-7 long basal conspicuous bristles inserted on a single-lobed tubercle

Clypeus shorter or equivalent to the eye length; gonocoxite basal tuft with 6-8 upper short spiniform bristles and three long basal conspicuous bristles inserted on a single-lobed tubercle(Fig. 3)

..Ev.(Bar.) chacuensis sp.nov.

4 (3) Gonocoxite basal tuft with 3-4 upper short spiniform bristles and 5-7 basal long conspicuous bristles inserted in two different lobes of the tubercle; paramere narrower in the middle of the segment ending in a rounded head (Fig. 7A)

Ev. (Bar.) corumbaensis

Gonocoxite basal tuft with two upper short spiniform bristles and four basal long conspicuous bristles inserted on a single-lobed tubercle; paramere less narrow in the middle of the segment ending in an ovoid-shaped head (Fig. 7B) Ev. (Bar.) spelunca

\section{Females}

1 Individual spermathecal ducts 1-1.5 times longer than the stem height of the genital fork; spermathecae $c a .3$ times wider than the individual ducts (pre-apical)..................(Cortelezzii complex)

\section{Ev. (Bar.) cortelezzii} Ev. (Bar.) sallesi

Individual spermathecal ducts 2-3 times longer than the stem height of the genital fork; spermathecae ca. 6 times wider than the individual ducts (pre-apical)...............................(Corumbaensis complex) 2

2 (1) Clypeus longer than the eye length.

Ev.(Bar.) corumbaensis

Ev. (Bar.) spelunca

Clypeus shorter than or equal to the eye length......

Ev.(Bar.)chacuensissp.nov.

\section{Acknowledgments}

We thank Matias Ariel Parras for the field and laboratory collaboration; Enzo Gomez for the technical support, and Maria Gabriela Quintana for her valuable comments on this manuscript. This work was supported by the Roemmers 
Argentinean Foundation, the Consejo Nacional de Investigaciones Científicas y Técnicas (CONICET) and BID PICT 12-2842.

\section{References Cited}

Carvalho, G. M., R. P. Brazil, C. C. Sanguinette, and J. D. Filho. 2011. Description of evandromyia spelunca, a new phlebotomine species of the cortelezzii complex, from a cave in Minas Gerais State, Brazil (Diptera: Psychodidae: Phlebotominae). Parasit. Vectors. 4: 158.

Forattini, O. P. 1973. Entomologia médica. Psychodidae, Phlebotominae, Leishmanioses, Bartonelose. Edgard Blücher Ltda., São Paulo, Brazil.

Fuenzalida, A. D., and M. G. Quintana. 2017. Description of Pintomyia salomoni sp. n., a new phlebotomine species from northwest Argentina. Med. Vet. Entomol. 31: 214-219.

Galati, E. A. B. 2003. Morfologia, terminologia de adultos e identificação dos táxons da América, pp. 53-175. In E.F. Rangel, R. Lainson (eds.), Flebotomíneos do bras. Fiocruz, Rio de Janeiro, Brazil.

Galati, E. A. B. 2017. Phlebotominae (Diptera, Psychodidae): Classificação, morfologia, terminologia e identificação de Adultos, Apostila - Disciplina PSP5127-1 Bioecologia e Identificação de Phlebotominae. Public Heath School University, São Paulo, Brazil. www.fsp.usp.br/ egalati

Galati, E. A. B., V. L. B. Nunes, E. T. Oshiro, and F. Almeida Rego Jr. 1989. Nova espécie de Phlebotominae, Lutzomyia corumbaensis, sp. n. (Diptera, Psychodidae) do complexo Lutzomyia cortelezzii. Rev. Bras. Entomol. 33: $465-475$.
Galati, E. A. B., F. Galvis-Ovallos, P. Lawyer, N. Léger, and J. Depaquit. 2017. An illustrated guide for characters and terminology used in descriptions of Phlebotominae (Diptera, Psychodidae). Parasite. 24: 26.

Rosa, J. R., O. D. Salomon, J. D. Andrade Filho, G. M. Carvalho, E. A. Szelag, M. Stein, E. S. Tapia, and R. P. Brazil. 2010. Phlebotomine sand flies (Diptera: Psychodidae) of the province of Chaco, Argentina. Neotrop. Entomol. 39: 303-305.

Rosa, J., D. P. Pereira, R. P. Brazil, J. D. Filho, O. Salomón, and E. Szelag. 2012. Natural infection of cortelezzii complex (Diptera: Psychodidae: Phlebotominae) with Leishmania braziliensis in Chaco, Argentina. Acta Trop. 123: 128-131.

Salomón, O. D., J. R. Rosa, M. Stein, M. G. Quintana, M. S. Fernández, A. M. Visintin, G. R. Spinelli, M. M. de Pascual, M. L. Molinari, M. L. Morán, et al. 2008. Phlebotominae (Diptera: Psycodidae) fauna in the Chaco region and Cutaneous Leishmaniasis transmission patterns in Argentina. Mem. Inst. Oswaldo Cruz. 103: 578-584.

Sudia, W. D., and R. W. Chamberlain. 1962. Battery-operated light trap, an improved model. Mosq. News. 22: 126-129.

Szelag, E. A., J. D. Filho, J. R. Rosa, M. A. Parras, M. G. Quintana, M. G. Quintana, and O. D. Salomon. 2016. Argentinian phlebotomine fauna, new records of Phlebotominae (Diptera: Psychodidae) for the country and the province of Chaco. Zootaxa. 4139: 427-430.

Visintin, A. M., M. D. Beranek, M. J. Amieva, J. R. Rosa, W. R. Almirón, and O. D. Salomón. 2016. Spread of Phlebotominae in temperate climates: province of Córdoba, Argentina. Mem. Inst. Oswaldo Cruz. 111: 75-78. 